\title{
Kesesuaian Pembangunan Rumah Susun Sederhana Sewa Terhadap Standar Perumahan Ideal di Sukoharjo
}

\author{
Isandi Nurul Hasanah, Murtanti Jani Rahayu, Rufia Andisetyana Putri
}

\author{
Program Studi Perencanaan Wilayah Dan Kota \\ Fakultas Teknik \\ Universitas Sebelas Maret, Surakarta \\ email: sanz_indikha@yahoo.com
}

\begin{abstract}
Construction of the rented simple flats is the option of government's policy to meet the needs of adequate housing for low-income. The rented simple flats in Sukoharjo already inhabited 3 blocks of 6 blocks. The degree of occupancy will indirectly reflect quality the construction of flats. The problem in this study is whether development the rented simple flats in Sukoharjo complies with the standar of ideal housing. The purpose of research is the degree of conformity the rented simple flats in Sukoharjo as the standar of ideal housing. The method is used the deductive research methods with quantitative research. The analysis technique is used the analysis of scoring on any variable of the standards of ideal housing. The conclusions from this research is that there are nine variables known as the factors that influence the development of the rented simple flats in Sukoharjo as the ideal flats. The variables that have been suitable with the standar of ideal housing are the policy, the price of rent and accessibily. However, some variables that have not been optimal like the infrastructures, material contruction and the others. Consequently, Sukoharjo's District Government and some of the parties concerned to repair deficiency and accommodate the needs of the community to achieve development the ideal flats.
\end{abstract}

Keywords: Contruction of rented simple flats, standards of ideal housing, scoring analysis

\section{PENDAHULUAN}

Menurut Yudohusodo (1991) rumah merupakan suatu cerminan dan pengejawantahan dari diri manusia yang hidup dalam suatu kesatuan dan kebersamaan dengan lingkungan alamnya guna meningkatkan taraf hidup bagi penghuninya. Rumah menjadi salah satu elemen penting yang sangat dibutuhkan manusia sebagai tempat untuk menyelenggarakan kehidupan manusia secara berkelanjutan.

Saat ini kebutuhan terhadap rumah cukup sulit untuk dipenuhi oleh setiap manusia. Hal ini disebabkan oleh laju pertumbuhan penduduk yang meningkat setiap tahunnya. Fenomena ini tentunya berbanding terbalik dengan kondisi lahan yang terbatas (Budihardjo, 1998).

Kabupaten Sukoharjo merupakan salah satu daerah yang mengalami fenomena tersebut. Menurut Badan Pusat Statistika Kabupaten Sukoharjo Tahun 2014 bahwa jumlah pendatang baru di Kabupaten Sukoharjo meningkat setiap tahunnya yaitu sekitar 1.259 orang. Selain itu, jumlah Rumah Tidak Layak Huni (RTLH) dan rumah kumuh di Kabupaten Sukoharjo cukup tinggi yaitu sekitar 40.819 unit atau sekitar 23\% (Rencana
Tata Ruang Wilayah Kabupaten Sukoharjo, 2011-2031). Oleh karena itu, untuk mengatasi hal tersebut, pemerintah membangun Rumah Susun Sederhana Sewa di Sukoharjo.

Rumah Susun Sederhana Sewa dibangun di Desa Gamping, Kelurahan Joho, Kecamatan Sukoharjo, Kabupaten Sukoharjo. Bangunan Rumah Susun Sederhana Sewa di Sukoharjo terdiri atas enam gedung yang dibangun dalam konsep twin block. Berdasarkan Peraturan Bupati Sukoharjo No. 48 Tahun 2014 tentang Pengelolaan Rumah Susun Sederhana Sewa di Sukoharjo, target pembangunan Rumah Susun Sederhana Sewa di Sukoharjo diprioritaskan untuk golongan masyarakat berpenghasilan rendah dan yang belum memiliki tempat tinggal di Kabupaten Sukoharjo.

Berdasarkan wawancara terhadap Kepala Dinas Pekerjaan Umum Kabupaten Sukoharjo bahwa rumah susun tersebut baru dihuni 3 blok antara lain blok A, B dan D dari 6 blok yang tersedia. Padahal di awal pembangunan, Rumah Susun Sederhana Sewa di Sukoharjo sudah banyak orang yang mengantri untuk menyewa unit hunian di sana bahkan melebihi kapasitas yang tersedia. Selain itu, berdasarkan observasi lapangan yang dilihat secara umum oleh peneliti, ternyata banyak beberapa 
bangunan dan fasilitas yang kondisinya kurang baik meskipun berada di tempat yang cukup strategis.

Pembangunan Rumah Susun Sederhana Sewa di Sukoharjo dapat tercapai dengan baik jika melakukan pemberdayaan pada masyarakat dan para pelaku kunci lainnya (Sasta dan Marlina, 2006), salah satunya adalah penghuni yang tinggal di Rumah Susun Sederhana Sewa di Sukoharjo. Oleh karena itu, peneliti ingin melihat bagaimana kesesuaian pembangunan Rumah Susun Sederhana Sewa di Sukoharjo terhadap standar perumahan ideal.

\section{TINJAUAN PUSTAKA}

Menurut Sugiyono (2009) bahwa tinjauan pustaka berisi ulasan atau penjelasan terhadap variabel yang akan diteliti melalui pendefinisian, uraian yang lengkap dan mendalam dari berbagai referensi sehingga ruang lingkup dan kedudukan terhadap hubungan antar variabel yang diteliti menjadi lebih jelas dan terarah.

Variabel penelitian tersebut diambil dari pendapat berbagai sumber atau para ahli, kemudian untuk melakukan sintesa variabel, peneliti membuat matriks pada setiap klasifikasi teori agar dapat terlihat kesamaan pendapat dari berbagai sumber sehingga dapat dirumuskan menjadi variabel yang sesuai.

\subsection{Teori Permintaan Perumahan}

Menurut Sukirno (2003) dalam ilmu ekonomi terdapat harga keseimbangan atau harga ekuilibrium dimana permintaan (demand) dan penawaran (supply) yang saling bertemu dan membentuk satu titik pertemuan dalam satuan harga dan kuantitas (jumlah barang).

\subsubsection{Teori Permintaan}

Menurut Mckenzie dan Betts (2006) dalam Purbosari (2012) bahwa permintaan pada perumahan dapat dilihat dari berbagai aspek antara lain jumlah unit perumahan yang dibutuhkan di dalam pasar dan komposisi perumahan seperti ukuran unit, usia, lokasi, kondisi, dan apakah unit-unit tersebut direncanakan untuk dijual kepada konsumen atau hanya untuk disewakan.

\subsubsection{Kurva Permintaan}

Menurut Sukirno (2003) bahwa kurva permintaan berbagai jenis barang pada umumnya menurun dari kiri ke kanan bawah. Kurva tersebut disebabkan oleh sifat hubungan antara harga dan jumlah yang diminta memiliki hubungan terbalik. Faktor-faktor yang dapat menggeser kurva permintaan salah satunya adalah faktor harga dimana perubahan sepanjang kurva permintaan berlaku apabila harga barang yang diminta menjadi makin tinggi atau makin menurun (Manurung, 2002), untuk lebih jelasnya dapat dilihat pada Gambar 1 seperti di bawah ini.

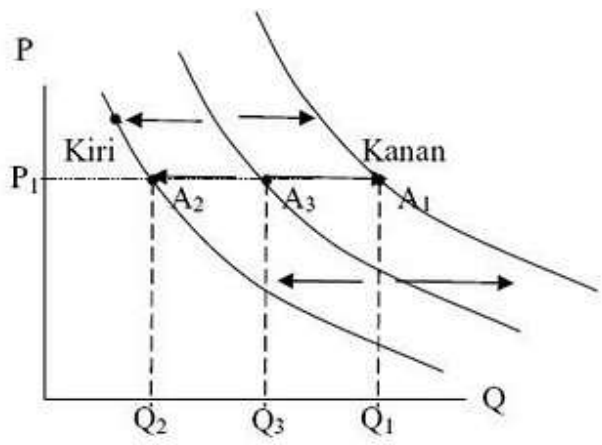

Gambar 1. Kurva Permintaan Barang (Manurung, 2002)

\subsection{Pembangunan Rumah Susun}

Berdasarkan Undang-Undang Nomor 20 Tahun 2011 adalah bangunan gedung bertingkat yang dibangun dalam suatu lingkungan yang terbagi dalam bagian-bagian yang distrukturkan secara fungsional, baik dalam arah horizontal maupun vertikal dan merupakan satuan-satuan yang masing-masing dapat dimiliki dan digunakan secara terpisah, terutama untuk tempat hunian yang dilengkapi dengan bagian bersama, benda bersama, dan tanah bersama.

\subsubsection{Tujuan Pembangunan Rumah Susun}

Pembangunan rumah susun adalah salah satu upaya untuk pemenuhan kebutuhan perumahan dan penanganan perumahan kumuh di Indonesia. Pemerintah terus gencar melaksanakan pembangunan rumah susun di kota besar sebagai usaha peremajaan kota dan upaya untuk memenuhi kebutuhan perumahan dengan pola yang vertikal yang diprioritaskan untuk masyarakat berpenghasilan rendah yang sulit mengakses rumah yang layak huni (Yudohusodo, 1991). 


\subsubsection{Peruntukkan Rumah Susun}

Menurut Undang-undang Nomor 20 Tahun 2011 tentang Rumah Susun, rumah susun di Indonesia dibedakan menjadi: rumah susun umum, rumah susun yang diselenggarakan untuk memenuhi rumah bagi masyarakat berpenghasilan menengah bawah dan berpenghasilan rendah; rumah susun khusus, rumah susun yang diselenggarakan oleh negara atau swasta untuk memenuhi kebutuhan khusus; rumah susun negara, rumah susun yang dimiliki negara dan berfungsi sebagai tempat tinggal atau hunian, sarana pembinaan keluarga, penunjang pelaksanaan tugas pejabat; dan rumah susun komersial merupakan rumah susun yang diselenggarakan untuk mendapatkan keuntungan. Rumah susun ini diperuntukkan bagi masyarakat menengah ke atas.

\subsection{Faktor Pembangunan Perumahan Ideal} Menurut Mirhad (1983) dalam Budihardjo (1998) bahwa pembangunan perumahan yang baik memperhatikan berikut ini :

1. Aspek teknis lingkungan : bukan daerah rawan bencana, kondisi tanah baik, mudah mendapat air bersih, listrik, pembuangan limbah dan mudah mendapat bahan bangunan.

2. Aspek tata guna tanah : tanah secara ekonomis lebih sukar dikembangkan secara produktif (bukan daerah persawahan, perkebunan, dan daerah usaha) dan sejauh mungkin dapat mempertahankan fungsi sebagai reservoir air tanah.

3. Aspek kesehatan : lokasi sebaiknya jauh dari lokasi pabrik, lokasi sebaiknya dipilih yang mudah untuk mendapatkan air minum, listrik dan utilitas lainnya.

4. Aspek politik ekonomis : memberikan kemudahan ekonomi pada penghuninya, mudah menjualnya karena lokasinya disukai oleh calon pembeli, lokasi sebaiknya mudah dicapai dari tempat kerja penghuni dan memberikan kemudahan pada penghuni dalam mengakses sekolah, puskesmas, perdagangan, peribadatan, pemerintahan dan sarana lainnya untuk kepentingan penghuninya.

\subsection{Standar Pembangunan Rumah Susun bagi Masyarakat Berpenghasilan Rendah}

Menurut Turner (1968) dalam Purbosari (2012) sebenarnya masyarakat berpenghasilan rendah sejatinya tidak menuntut rumah yang mewah, tetapi lebih mengharapkan tersedianya ruang yang memadai untuk mewadahi kegiatan kehidupan mereka antara lain harga sewa yang terjangkau, prasarana yang memadai, ketersediaan sarana dan memiliki aksesibilitas yang baik. Selain itu, untuk masyarakat berpenghasilan rendah, pilihan perumahan lebih ditekankan pada aspek lokasi yang memberikan peluang lapangan kerja dan hemat biaya transportasi. Sedangkan menurut Miles (2001) bahwa perumahan untuk masyarakat berpenghasilan rendah harus mempertimbangkan berbagai aspek antara lain kondisi fisik lahan, ketersediaan sarana, prasarana, ketersediaan moda transportasi, aksesibilitas dan harga lahan.

\subsection{Sintesa Teori}

Dari teori di atas, variabel yang mendukung standar perumahan ideal antara lain kebijakan, harga sewa, sosial ekonomi, aksesibilitas, tersedianya sarana, pelayanan prasarana, status lahan dan kondisi kontruksi bangunan.

\section{METODE PENELITIAN}

Menurut Sugiyono (2009) bahwa metode penelitian adalah cara ilmiah untuk mendapatkan data dengan tujuan tertentu dimana kegiatan penelitian harus rasional, empiris dan sistematis.

\subsection{Ruang Lingkup}

Fokus objek yang akan diteliti adalah Rumah Susun Sederhana Sewa yang berada di Desa Gamping, Kelurahan Joho, Kecamatan Sukoharjo, Kabupaten Sukoharjo. Berdasarkan observasi lapangan bahwa lokasi rumah susun berada di tempat yang cukup strategis dimana dekat dengan beberapa tempat yang penting. Rumah Susun Sederhana Sewa di Sukoharjo memiliki 6 blok, namun hingga sampai saat ini baru 3 blok yang sudah dihuni oleh masyarakat berpenghasilan rendah yaitu blok A, B dan D.

\subsection{Metode Analisis}

Penelitian ini menggunakan metode pendekatan deduktif dimana peneliti mengoperasionalkan variabel yang diturunkan dari beberapa teori melalui sintesa. Jenis penelitian yang digunakan adalah jenis penelitian kuantitatif.

\subsection{Variabel Penelitian}

Menurut Sugiyono (2009) bahwa variabel penelitian adalah kesimpulan dan hasil kajian yang ditetapkan oleh peneliti untuk 
mempelajari segala informasi yang berkaitan dengan penelitian terkait yang mempunyai variasi dan nilai tertentu. Variabel dan indikator penelitian dapat dilihat pada Lampiran.

\subsection{Teknik Pengumpulan Data}

Teknik pengumpulan data adalah tahapan awal dalam melakukan penelitian untuk memperoleh data pendukung sehingga dapat menganalisis setiap variabel yang akan dibahas dalam penelitian ini. Teknik pengumpulan data yang digunakan dalam penelitian ini adalah teknik pengumpulan data primer dan sekunder. Teknik pengumpulan data primer dilakukan dengan observasi lapangan, penyebaran angket dan wawancara, sedangkan teknik pengumpulan data sekunder diperoleh melalui studi dokumen dari institusi atau pihak yang berwenang. Untuk lebih jelasnya akan diuraikan sebagai berikut ini.

\subsubsection{Observasi Lapangan}

Data yang diambil melalui observasi lapangan adalah variabel ketersediaan sarana dan aksesibilitas (data jarak ke tempat kerja, transportasi, berbagai fasilitas penting). Data tersebut akan dianalisis melalui Geographic Information System (GIS) dan Google Earth dan kemudian akan dikalikan dengan indikator yang diberi nilai sesuai dengan rumus yang ada.

\subsubsection{Penyebaran Angket}

Penyebaran angket yang dilakukan dalam penelitian ini dimaksudkan untuk memperoleh informasi yang berkaitan dengan faktor yang berpengaruh terhadap isu penelitian ini antara lain variabel harga sewa, kondisi sosial ekonomi, prasarana dan sub variabel komponen fisik kontruksi bangunan serta sub variabel kedekatan dengan tempat kerja.

\subsubsection{Wawancara}

Wawancara dilakukan dengan Kepala Dinas Pekerjaan Umum Kabupaten Sukoharjo sebagai pengelola Rumah Susun Sederhana Sewa di Sukoharjo, ketua paguyuban dan penghuni Rumah Susun Sederhana Sewa di Sukoharjo untuk mendapatkan kondisi yang ada di rumah susun tersebut.

\subsubsection{Studi Dokumen}

Pada tahapan ini, peneliti melihat data dari institusi atau lembaga yang berkaitan dengan isu penelitian. Data tersebut meliputi data aksesibilitas (rute trayek Desa Joho) yang berasal dari Dinas Perhubungan Informasi dan Komunikasi Kabupaten Sukoharjo sedangkan data profil Rumah Susun Sederhana Sewa di Sukoharjo, data jumlah penghuni rumah susun, data ukuran tempat parkir, dan data ukuran hunian rumah susun berasal dari Dinas Pekerjaan Umum Kabupaten Sukoharjo.

\subsection{Populasi Penelitian}

Populasi penelitian adalah wilayah yang akan diteliti yang terdiri atas objek atau subjek yang mempunyai kuantitas dan karakteristik tertentu yang ditetapkan oleh peneliti untuk dipelajari, dianalisis kemudian ditarik kesimpulannya (Sugiyono, 2009). Untuk mengetahui kesesuaian pembangunan Rumah Susun Sederhana Sewa di Sukoharjo terhadap standar perumahan yang ideal, maka batasan populasi dalam penelitian ini adalah penghuni Rumah Susun Sederhana Sewa di Sukoharjo. Berikut ini adalah jumlah penghuni yang tinggal di Rumah Susun Sederhana Sewa di Sukoharjo.

Tabel 1. Jumlah Penghuni Rumah Susun Sederhana Sewa di Sukoharjo

\begin{tabular}{|c|c|c|c|}
\hline Blok & Lantai & $\begin{array}{c}\text { Jumlah } \\
\text { KK }\end{array}$ & $\begin{array}{c}\text { Jumlah KK } \\
\text { Per Blok }\end{array}$ \\
\hline \multirow{3}{*}{$\begin{array}{l}\text { Blok } \\
\text { A ( } 48 \\
\text { unit) }\end{array}$} & Lantai 1 & $16 \mathrm{KK}$ & \\
\hline & Lantai 2 & $13 \mathrm{KK}$ & \\
\hline & Lantai 3 & $15 \mathrm{KK}$ & $44 \mathrm{KK}$ \\
\hline \multirow{3}{*}{$\begin{array}{l}\text { Blok } \\
\text { B (48 } \\
\text { unit) }\end{array}$} & Lantai 1 & $15 \mathrm{KK}$ & \\
\hline & Lantai 2 & $12 \mathrm{KK}$ & \\
\hline & Lantai 3 & $9 \mathrm{KK}$ & $36 \mathrm{KK}$ \\
\hline \multirow{4}{*}{$\begin{array}{l}\text { Blok } \\
\text { C (52 } \\
\text { unit) }\end{array}$} & Lantai Dasar & $2 \mathrm{KK}$ & \\
\hline & Lantai 1 & $14 \mathrm{KK}$ & \\
\hline & Lantai 2 & $12 \mathrm{KK}$ & \\
\hline & Lantai 3 & $14 \mathrm{KK}$ & $42 \mathrm{KK}$ \\
\hline \multicolumn{2}{|c|}{ Jumlah Total } & $122 \mathrm{KK}$ & $122 \mathrm{KK}$ \\
\hline
\end{tabular}

(Dinas Pekerjaan Umum Kabupaten Sukoharjo, 2016)

\subsection{Teknik Analisis}

Untuk mengetahui hasil skoring pada semua variabel, peneliti melakukan skoring dengan berbagai tahap antara lain analisis skoring kesesuaian setiap variabel, analisis skoring setiap rincian sub variabel, analisis skoring berdasarkan data yang diperoleh (kuesioner, observasi lapangan dan studi dokumen) dan analisis skoring tingkat kesesuaian Rumah Susun Sederhana Sewa di Sukoharjo terhadap standar perumahan ideal.

\subsubsection{Analisis Skoring Kesesuaian Setiap Variabel}

Teknis analisis data ini dilakukan dengan pemberian skoring pada masing-masing 
variabel. Variabel tersebut terdiri atas sub variabel dan rincian sub variabel dimana memiliki perhitungan parameter yang berbedabeda. Teknis analisis data ini dilakukan untuk mempermudah peneliti untuk mengidentifikasi setiap variabel penelitian yang kemudian diklasifikasikan ke dalam kategori "sangat sesuai", "sesuai" dan "tidak sesuai".

Tabel 2. Penilaian Kesesuaian Variabel terhadap Standar Perumahan Ideal

\begin{tabular}{|l|c|}
\hline \multicolumn{1}{|c|}{ Keterangan } & Skor \\
\hline $\begin{array}{l}\text { Nilai variabel yang diperoleh sudah sangat } \\
\text { sesuai dengan standar perumahan ideal }\end{array}$ & 3 \\
\hline $\begin{array}{l}\text { Nilai variabel yang diperoleh sudah sesuai } \\
\text { dengan standar perumahan ideal }\end{array}$ & 2 \\
\hline $\begin{array}{l}\text { Nilai variabel yang diperoleh tidak sesuai } \\
\text { dengan standar perumahan ideal }\end{array}$ & 1 \\
\hline
\end{tabular}

Untuk memberikan penilaian skoring pada setiap variabel yang diperoleh dari penjumlahan akumulasi setiap parameter, peneliti menentukan skoring dengan rumus interval. Interval akan mempermudah peneliti untuk dapat menginterpretasikan setiap variabelnya dan dimasukkan ke dalam klasifikasi tingkat kesesuaian yang masingmasing diberi skor 3, 2 dan 1 untuk setiap variabelnya. Penilaian skoring pada setiap variabel dapat diperoleh melalui rumus di bawah ini.

$\begin{aligned} \text { Interval } & =(\text { Nilai Tertingi }- \text { Nilai Terendah }): \text { Jumlah Kelas } \\ & =(3-1): 3 \\ & =0,66\end{aligned}$

Dari rumus tersebut, dapat diperoleh klasifikasi tingkat kesesuaian setiap variabel seperti berikut ini.

\subsubsection{Analisis Skoring Setiap Rincian Sub Variabel}

Setiap variabel diberikan nilai skoring 3 dan pembagian penilaian skoring pada setiap variabel berbeda-beda tergantung pada jumlah sub variabel atau rincian sub variabel. Skor 3 tersebut dibagi dengan jumlah sub variabel atau rincian sub variabel yang kemudian dibagi lagi menjadi 3 agar setiap indikator tingkat kesesuaian mendapatkan nilai berdasarkan perhitungan masing-masing.

\subsubsection{Analisis Skoring Tingkat} Kesesuaian Rumah Susun Sederhana Sewa di Sukoharjo terhadap Standar Perumahan Ideal

Setiap variabel yang terkait dengan tingkat kesesuaian Rumah Susun Sederhana Sewa di
Sukoharjo terhadap standar perumahan ideal dianalisis terlebih dahulu menggunakan skoring, kemudian dilakukan analisis secara keseluruhan untuk mengetahui tingkat kesesuaiannya terhadap standar perumahan ideal. Dalam penelitian ini terdiri dari 9 variabel, maka didapatkan nilai maksimalnya adalah 27 melalui hasil perkalian dari skor tertinggi (3) dengan jumlah variabel (9), sedangkan nilai minimal yang didapatkan adalah 9, melalui hasil perkalian nilai skor terendah (1) dengan jumlah variabel (9). Dengan begitu akan didapatkan tingkat kesesuaian rumah susun terhadap standar perumahan ideal. Untuk selanjutnya dilakukan perhitungan dalam menentukan interval sebagai berikut ini :

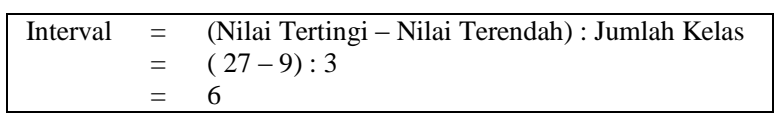

Setelah didapatkan nilai interval, maka dapat diketahui kategori hasil skoring seperti berikut ini :

Keterangan :

1. Hasil skoring memiliki nilai di antara $22-$ 27, maka masuk ke dalam kategori sangat sesuai dimana pembangunan Rumah Susun Sederhana Sewa di Sukoharjo sangat sesuai dengan standar perumahan ideal;

2. Hasil skoring memiliki nilai di antara $16-$ 21, maka masuk ke dalam kategori cukup sesuai dimana pembangunan Rumah Susun Sederhana Sewa di Sukoharjo sesuai dengan standar perumahan ideal;

3. Hasil skoring memiliki nilai di antara $9-$ 15, maka masuk ke dalam kategori tidak sesuai dimana pembangunan Rumah Susun Sederhana Sewa di Sukoharjo tidak sesuai dengan standar perumahan ideal.

\section{HASIL DAN PEMBAHASAN}

Hasil dan pembahasan akan menjelaskan kondisi Rumah Susun Sederhana Sewa di Sukoharjo kemudian ditinjau terhadap teori yang terkait dengan standar perumahan ideal.

\subsection{Kebijakan}

Kebijakan pembangunan Rumah Susun Sederhana Sewa di Sukoharjo sudah sangat sesuai dengan arahan Rencana Tata Ruang Wilayah Kabupaten Sukoharjo Tahun 2011 2031 bahwa Desa Joho dikembangkan untuk kawasan permukiman dan berada di zona kawasan budidaya, sedangkan intensitas kepadatan bangunan sudah sangat sesuai 
dengan ketentuan yang terkait antara lain Koefisien Dasar Bangunan (KDB) berada di antara $40 \%$ - $60 \%$ dan Koefisien Lantai Bangunan (KLB) adalah 1,6. Nilai ini sudah sangat sesuai dengan standar perumahan ideal.

\subsection{Harga Sewa}

Harga sewa mayoritas di bawah ketetapan O'Sullivan (2012) yaitu di bawah Rp 449,000,00. Harga sewa ini sudah termasuk biaya sewa, air, listrik dan biaya pemeliharaan lainnya. Harga sewa Rumah Susun Sederhana Sewa di Sukoharjo ini sangat sesuai dengan pendapatan penghuni rumah susun yang mayoritas masyarakat berpenghasilan rendah.

\subsection{Jenis Penghuni Rusun}

Kondisi penghasilan penghuni Rumah Susun Sederhana Sewa di Sukoharjo berbanding lurus dengan jenis pekerjaan yang tinggal di sana. Faktor tersebut sangat sesuai dengan target pembangunan Rumah Susun Sederhana Sewa yang telah tertuang di dalam Peraturan Bupati Sukoharjo No. 48 Tahun 2014 dimana masyarakat berpenghasilan rendah biasanya bekerja di sektor informal, sedangkan jumlah penghuni di sana tidak sesuai dimana mayoritas dihuni 5 orang. Oleh karena itu, jenis penghuni rusun termasuk ke dalam klasifikasi sesuai dengan standar perumahan ideal.

\subsection{Aksesibilitas}

Aksesibilitas sudah sangat sesuai dengan teori terkait dan standar perumahan ideal kecuali jarak ke tempat kerja yang masuk ke dalam kategori tidak sesuai. Hal ini dikarenakan akses ke tempat kerja yang cukup jauh yaitu mayoritas di luar Kecamatan Sukoharjo dan Kabupaten Sukoharjo.

\subsection{Sarana}

Sarana yang tersedia sudah sesuai dengan standar perumahan ideal. Beberapa sarana yang tersedia sudah sesuai untuk melayani kegiatan penghuni Rumah Susun Sederhana Sewa tersebut antara lain pelayanan peningkatan ilmu, derajat kesehatan, kebutuhan sehari-hari, pelayanan rohani manusia dan penampungan kendaraan bermotor di setiap unit blok Rumah Susun Sederhana Sewa di Sukoharjo.

\subsection{Prasarana}

Kondisi prasarana di lingkungan Rumah Susun Sederhana Sewa di Sukoharjo tidak sesuai dengan standar perumahan yang ideal dimana kondisi drainase cukup buruk, pelayanan pengakutan sampah yang masih kurang baik dan kapasitas listrik di bawah ketentuan terkait yaitu di bawah 450 Va. Namun, untuk prasarana air sudah memadai dimana PDAM yang digunakan oleh penghuni rumah susun sudah dapat melayani kegiatan penghuninya dan limbah sudah dibuang melalui septic tank.

\subsection{Status Lahan}

Status lahan di Rumah Susun Sederhana Sewa di Sukoharjo adalah Hak Guna Bangunan (HGB). Status ini dapat dikatakan sesuai meskipun hak guna bangunan bersifat sementara dimana memiliki masa perpanjangan kontrak sekitar 30 tahun dan dapat diperpanjang lagi jika ada kesepakatan antara kedua belah pihak.

\subsection{Fisik Dasar}

Berdasarkan ketentuan Rencana Tata Ruang Wilayah Kabupaten Sukoharjo Tahun 20112031 bahwa sektor fisik dasar sudah sesuai dimana dibangun di Desa Joho yang merupakan kawasan budidaya sehingga relatif aman didirikan bangunan karena memiliki kelerengan datar yaitu 0-3\%. Jenis tanah di Desa Joho adalah tanah alluvial sehingga tidak perlu membutuhkan rekayasa teknis dalam mendirikan pembangunan Rumah Susun Sederhana Sewa di Sukoharjo.

\subsection{Kontruksi Bangunan}

Bahan kontruksi bangunan mayoritas menggunakan bahan semi permanen artinya sudah sesuai dengan standar perumahan ideal. Atap Rumah Susun Sederhana Sewa di Sukoharjo menggunakan seng, bahan plafon dari gypsum, bahan dinding dari batu batako dan lantai menggunakan bahan semen. Meskipun begitu, bahan semi permanen tidak sebaik bahan permanen karena sifatnya tidak terlalu kuat dan tahan lama terhadap cuaca baik hujan, kemarau dan lainnya serta kurang dapat menyesuaikan dengan suhu di dalam ruangan, sedangkan ukuran unit rumah susun adalah $18 \mathrm{~m}^{2}$ masih nyaman untuk dihuni. Oleh karena itu, kontruksi bangunan termasuk ke dalam klasifikasi yang sesuai dengan standar perumahan ideal.

\section{KESIMPULAN}


Total nilai skor semua variabel adalah 21 berada di antara $16-21$. Nilai ini termasuk ke dalam kategori sudah sesuai dengan standar perumahan ideal. Dari hasil analisis tersebut, terdapat 3 variabel yang sudah sangat sesuai dengan standar perumahan ideal, sedangkan variabel lainnya termasuk ke dalam klasifikasi sesuai. Untuk tingkat kesesuaian variabel terhadap standar perumahan yang ideal akan dijelaskan pada Tabel 4 di bawah ini.

Tabel 4. Hasil Analisis Kesesuaian Pembangunan Rumah Susun Sederhana Sewa di Sukoharjo terhadap Standar Perumahan Ideal

\begin{tabular}{|c|c|c|c|}
\hline No. & Variabel & Hasil & Keterangan \\
\hline 1. & Kebijakan & 3 & Sangat Sesuai \\
\hline 2. & Harga Sewa & 3 & Sangat Sesuai \\
\hline 3. & $\begin{array}{l}\text { Jenis Penghuni } \\
\text { Rusun }\end{array}$ & 2 & Sesuai \\
\hline 4. & Aksesibilitas & 3 & Sangat Sesuai \\
\hline 5. & Sarana & 2 & Sesuai \\
\hline 6. & Prasarana & 1 & Tidak Sesuai \\
\hline 7. & Status Lahan & 2 & Sesuai \\
\hline 8. & Fisik Dasar & 3 & Sangat Sesuai \\
\hline 9. & Kontruksi Bangunan & 2 & Sesuai \\
\hline & Jumlah & 21 & Sesuai \\
\hline
\end{tabular}

Oleh karena itu, berdasarkan penelitian yang telah dilakukan, maka diperlukan evaluasi terhadap beberapa aspek yang belum memenuhi standar perumahan yang ideal antara lain perlunya peningkatan koordinasi antara pemerintah dengan ketua paguyuban maupun penghuni Rumah Susun Sederhana Sewa untuk dapat menampung aspirasi setiap penghuni di sana dan kesadaran para penghuni dalam menjaga Rumah Susun Sederhana Sewa di Sukoharjo, memperbaiki sarana, prasarana dan aspek lainnya untuk mencapai rumah susun yang sehat dan layak huni.

\section{REFERENSI}

Badan Pusat Statistika Kabupaten Sukoharjo Tahun 2014

Barton, Hugh. 2000. Healthy Urban Planning. London: Spon Press

Budihardjo, Eko. 1998. Percikan Masalah Arsitektur Perumahan Perkotaan. Yogyakarta: Gajah Mada University Press.

Chiara, Joseph. 1995. Time-Saver Standards for Housing and Residential Development. New York: Mc Graw Hill Book Company

Dinas Pekerjaan Umum Kabupaten Sukoharjo Tahun 2016

Frick, Heinz. 1980. Kontruksi Bangunan. Yogyakarta: Penerbit Yayasan Kanisius
Jayadinata, Johara. 1999. Tata Guna Tanah dalam Perencanaan Perdesaan, Perkotaan dan Wilayah. Bandung: ITB

Keputusan Gubernur Jawa Tengah No. 560/66/2015 tentang Batas Upah Minimum Kabupaten Sukoharjo

Keputusan Menteri Pekerjaan Umum No. 20/KPTS/1986 tentang Pedoman Pembangunan Perumahan Sederhana Tidak Bersusun

Keputusan Menteri Permukiman dan Prasarana Wilayah No. 534/KPTS/M/2001 tentang Pedoman Penentuan Standar Pelayanan Minimal Bidang Penatan Ruang, Perumahan dan Permukiman dan Pekerjaan Umum

Manurung, Mandala. 2002. Teori Ekonomi Mikro Suatu Pengantar. Jakarta: Fakultas Teknik Universitas Indonesia

Miles, Mike E. 2001. Real Estate Development : Principles and Process Third Edition. Washington DC: The Urban Land Institute Mirsa, Rinaldi. 2012. Elemen Tata Ruang Kota. Jakarta: Graha Ilmu

O'Sullivan, Arthur. 2012. Urban Economics Eight Edition. New York: Mc Graw Hill International Edition

Peraturan Bupati Sukoharjo No. 48 Tahun 2014 tentang Pengelolaan Rumah Susun

Peraturan Menteri Negara Perumahan Rakyat No. 11/Permen/M/2008 tentang Pedoman Keserasian Kawasan Perumahan dan Permukiman

Prima, Amos. 2013. Kesesuaian Resettlement Hunian Bagi Masyarakat Berpenghasilan Rendah Di Bantaran Sungai Pepe Kelurahan Sudiroprajan Kota Surakarta. Program Studi Perencanaan Wilayah dan Kota Fakultas Teknik Universitas Sebelas Maret

Purbosari, Annisa. 2012. Analisis Faktorfaktor Yang Mempengaruhi Keputusan Bertempat Tinggal di Kota Bekasi Bagi Penduduk Migran Berpenghasilan Rendah Yang Bekerja di Kota Jakarta. Semarang. Universitas Diponegoro

Rencana Tata Ruang Wilayah Kabupaten Sukoharjo Tahun 2011 - 2031

Sasta, S dan Marlina. 2006. Kebijakan Pemerintah Tentang Lingkungan Permukiman.

http://bojhezjanur.blogspot.co.id/2012/02/ kebijakan-pemerintah-tentanglingkungan.html. 
Standar Nasional Indonesia 03-1733-2004 Tentang Tata Cara Perencanaan Lingkungan Perumahan Di Perkotaan

Sugiyono. 2009. Metode Penelitian Kuantitatif, Kualitatif, dan $R \quad \& \quad D$. Bandung: Alfabeta CV

Sukirno, Sadono. 2003. Pengantar Teori Mikroekonomi Edisi Ketiga. Jakarta : Grafindo

Surat Keputusan Menteri Pertanian No. 837/KPTS/Um/11/1980 tentang Kriteria dan Tata Cara Penetapan Hutan Lindung

Tamin, Ofryar Z. 2000. Perencanaan dan Permodelan Transportasi.. Bandung: Penerbit ITB

Tobing, Rumiati R. 2012. The influence of design factors toward the thermal comfort in flats. Research Institute for Human Settlements. Bandung. Jurnal Permukiman. Vol. 7 No. 2 August 2012

Triyuli, Wienty. 2011. Model Rumah Bagi Keluarga Muda Berpenghasilan rendah di Kota Palembang Berdasarkan Preferensi dan Perspektif Perkembangan Keluarga. Program Studi Arsitektur Fakultas Teknik Universitas Sriwijaya: Indralaya

Undang-Undang Nomor 20 Tahun 2011 tentang Rumah Susun

Undang-undang Nomor 5 Tahun 1960 tentang Peraturan Dasar Pokok-Pokok Agraria

Yudohusodo, Siswono. 1991. Rumah Untuk Seluruh Rakyat. Jakarta 